Advanced Materials Center, Guangdong Welding Institute (China-Ukraine E.O. Paton Institute of Welding). Guangzhou, 510651 PR. China

\title{
HIGH CYCLE FATIGUE PROPERTY OF ELECTRON BEAM WELDED THICK SECTION Ti-6Al-4V PLATES
}

\begin{abstract}
The 100mm thickness Ti-6Al-4V plates were welded by the electron beam EBW method. Micro-structures and mechanical properties including tensile and fatigue fracture behavior of the joint have been studied. The results shown that the joint has obviously textural and mechanical heterogeneity in the thickness direction, the joint show excellentfatigue resistance though the middle layer of the joint has lower fatigue life at the same stress and survival rate. The fatigue crack initiates from the free surface of the specimen by the transgranular fracture mode. The fatigue deformation depicted by the dislocations of the joint in each layer is adapt to the planar-slip mechanism.. [dx.doi.org/10.29010/88.10]
\end{abstract}

Keywords: Ti-6Al-4V; microstructure; mechanical property; fatigue.

\section{Introduction}

Titanium alloy Ti-6Al-4V is one of the important base materials in the manufacture of aircraft and marine industries [1]. The Ti-6Al-4V titanium alloy has good weldability and corrosion resistance. However, in the case of the heavypiece parts (the thickness $\geq 30 \mathrm{~mm}$ ), there have been few methods could be chosen to supply good welding quality besides the EBW and tungsten inert gas welding (TIG) methods. Actually, the casting, forging and heat treating states of the pieces could greatly influence the heterogeneity of the mechanical property of the welding joint. Our former study revealed that the EBW welding seam has coarse $\beta$ phase and spiculate $\alpha$ ' phase, and the columnar crystals grow from the seam edge to the central line from both sides, moreover the grain size has the trend to decreases gradually from the upper side to the lower side in the vertical direction, although there may be anomaly grain growth in some local areas, for the EBW seam, there are also two defect concentration areas located near the seam surface and the nail tip. It has been known that the seam fusion zone of the Ti- $6 \mathrm{Al}-4 \mathrm{~V}$ have better tensile strength than that of the base metal because of the martensite phases in the seam, and the fatigue property of the joint is determined by the near-surface defects, moreover the seam zone have better fatigue strength than that of the base metal. The fatigue crack propagation rate of the fusion zone could be decreased by the ageing process, and the severe tortuous cracks have good crack propagation resistance. It could be seen that the fatigue property of the Ti-6Al-4V joint has been studied in various views, however most publication studies were done to the plate thickness lower than $30 \mathrm{~mm}$ [2-5]. As known, the fatigue properties of the joint will be different in the thickness direction of the joint. It is interesting to reveal the heterogeneity of the fatigue property of the heavy piece Ti-6Al-4V and found out the characteristics.

\section{Experimental}

The Ti-6Al-4V heavy pieces $\left(600 \times 150 \times 100 \mathrm{~mm}^{3}\right)$ have been heat treated at $750{ }^{\circ} \mathrm{C}$ for $2 \mathrm{hr}$ before the EBW welding. The as-welded joint was divided to 3 layers (layer $l_{1}, l_{2}$ and $l_{3}$ ) for the fatigue property investigation(Fig.1a). The fatigue specimens were cut from different layers to characterize the fatigue properties in the thickness directions, see Fig.1b. The specimens for the micrographs were polished by the abrasive polishing machine, cleaned by the acetone and hence etched by the distilled water, hydrofluoric acid (HF) and nitric acid $\mathrm{HNO}_{3}$ combinations. The microstructures of the specimens were investigated by the optical microscope (Axio Imager.M2m, ZEISS). The fatigue properties of the joint at different layers were tested by the $\mathrm{HF}$ fatigue testing machine (QBG-20, Changchun, CCQB), the oneway peak load is $100 \mathrm{KN}$, the cycle frequency is $100 \mathrm{~Hz}$, the cyclic waveform is the sinusoid. Six stress levels were chosen in at least 8 groups of tests. The cross-section morphologies of the fatigue fracture were observed by the scanning electron microscope (S-3400, Hitachi), and the microstructures of the fatigue fractures were analyzed by the transmission electron microscope (JEM-2100, JEOL). 


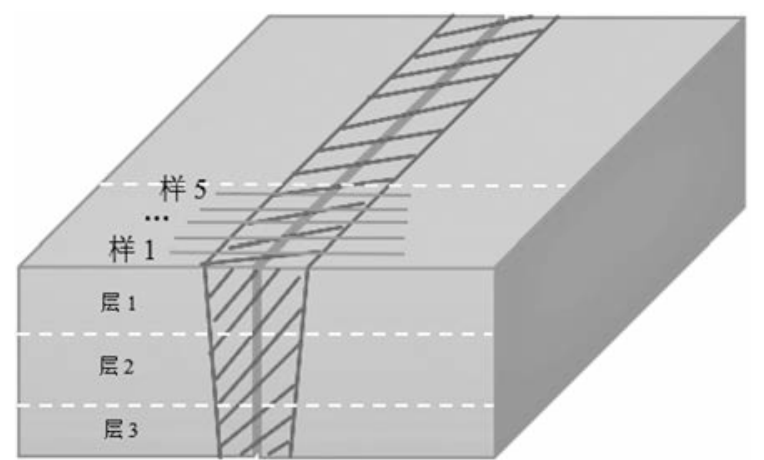

$a$
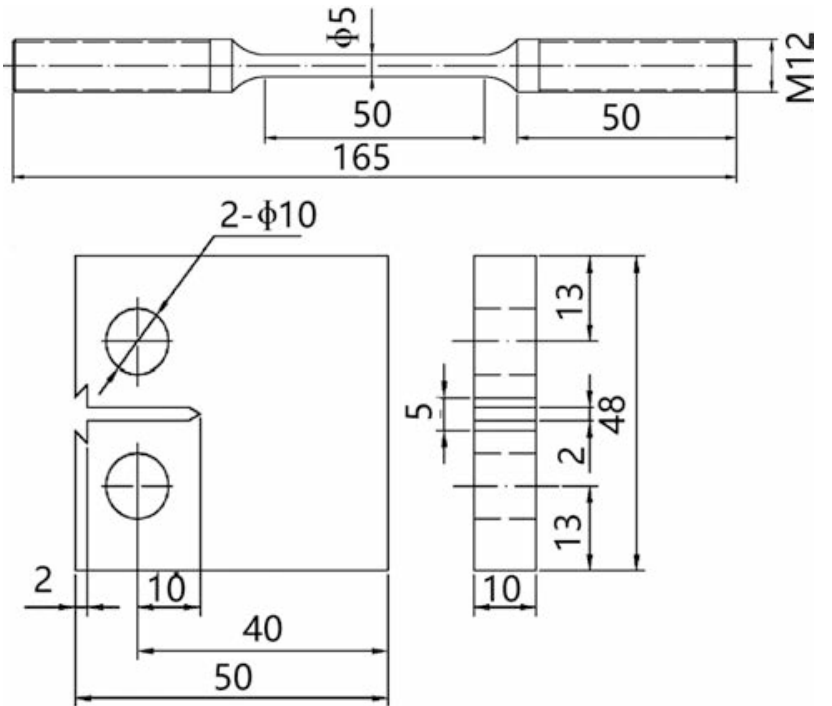

50

Fig. 1. Fatigue specimens and cutting method, $a$. cutting position of fatigue specimen, $b$. fatigue specimens and fatigue crack propagation specimen

\section{Results and discussions}

\subsection{Microstructure heterogeneity}

The microstructures of the seam zone, base metal and the heat affecting zone (HAZ) of the joint can be seen in Fig.2. The microstructures of the seam zone and the HAZ were shown from layer1 to layer5 of the joint. The gaps between the sampling positions of the micrograph in different layers are 10mm (Fig.2a). The base metal has equiaxed structure (Fig.2b). It can also be seen that the seam zone has basket-weave microstructures. The acicular martensite phases interweave with several interfaces differentiate the dendrite orientation. From layer 1 to layer 3, the microstructures of the seam zone have almost the same morphology and metallurgical characteristic, just have different acicular martensite distribution and orientation because of the different observation positions and view angles. Furthermore, the microstructure in layer 3 has more dendritic crystals and the texture is finer than those of the layer1 and layer 2. And the microstruc- tures of the layer 4 and layer 5 have further finer texture than that of the layer 3 . The seam textures are coincident with the as-known characteristics, however the texture difference between the area near the nail tip and the area close to the seam surface is bigger because the relatively higher thickness. The metallurgical characteristics were highly influenced by the heat input and radiation. The layers close to the seam surface has more heat input and the phases has the conditions to grow up before the formation of the lower half seam, moreover the layer 4 and layer 5 have better heat radiation conditions because being close to the radiation helping facilities.
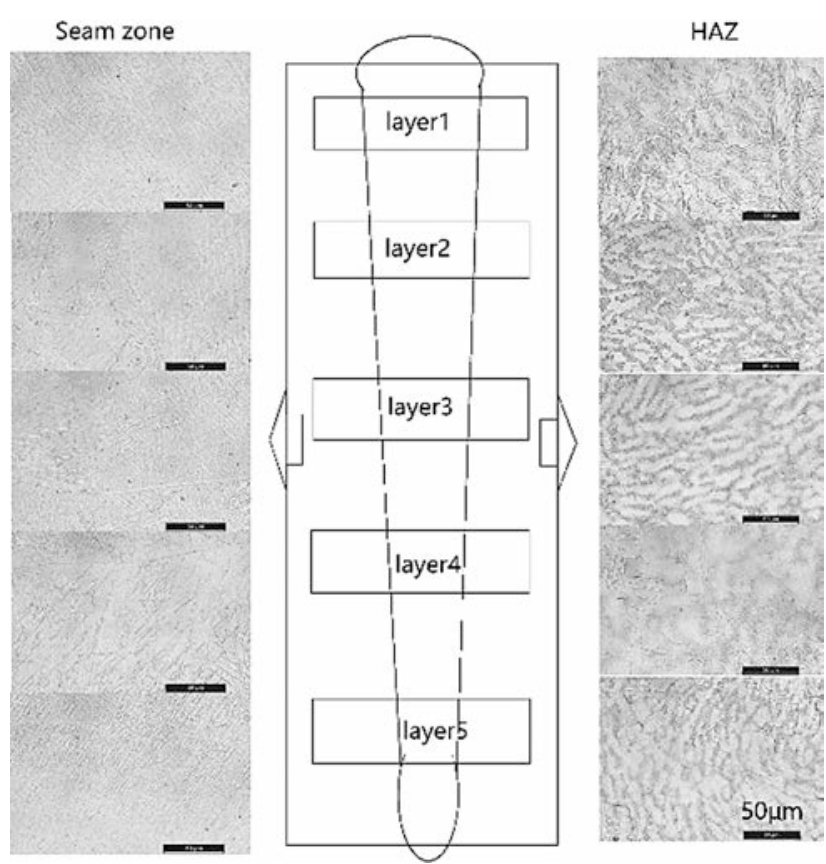

$a$

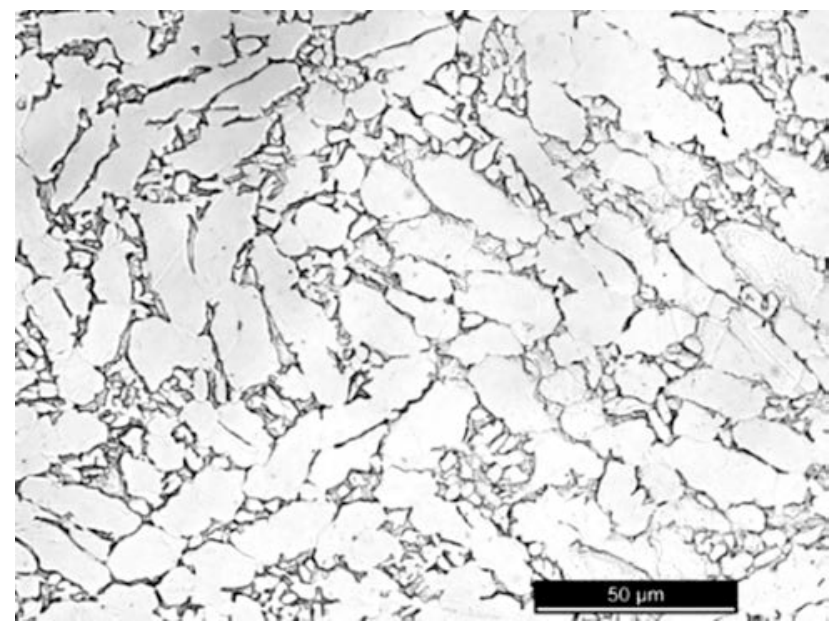

$b$

Fig.2. Microstructures of the joint $a$. microstructures of the seam zone and the HAZ in the thickness direction, $b$. microstructure of the base metal 
It can be seen in Fig. $2 a$ that layer 1 has widmannstatten structure, in which the lamellar martensite and a few acicular martensite are the main phases. In the layer 2 , the recrystallization happened and the microstructure of layer 2 began to transit to the crumby structure. The layer 3 mainly has crumby structure, and more acicular martensite phase could be found in layer 4 . In the layer 5, the microstructure began to transit to basket-weave structure. It is clearly that, in the heat-treated zone, the microstructures have the trend to change from widmannstatten structure, crumby structure to basket-weave structure in the thickness direction. This trend could be attributed to the cooling speed increased gradually in the thickness direction, the lower cooling speed gave the condition to form the widmannstatten structure, the higher cooling speed facilitate the formation of the acicular martensite, hence the basket-weave structure would form when the cooling speed broke the threshold value, which has been convinced. The heterogeneity in the thickness direction will inevitably give influence on the mechanical properties of the joint.

\subsection{Fatigue property}

The Fig. 3 showed the fatigue S-N curves of different layers $\left(l_{1}, l_{2}\right.$ and $\left.l_{3}\right)$ of the joint. The average value of the specimen and the standard deviation were calculated by formula 1 and formula 2, in which the $\bar{x}$ represent the average value of the specimen, the $x_{k}$ is the logarithm value of specimens, $N_{i}$ is the fatigue life of the specimen and $s$ is the standard deviation of the specimens.

$$
\bar{x}=\frac{1}{n} \sum_{k=1}^{n} x_{k}, \quad x_{k}=\lg \left(N_{i}\right)
$$
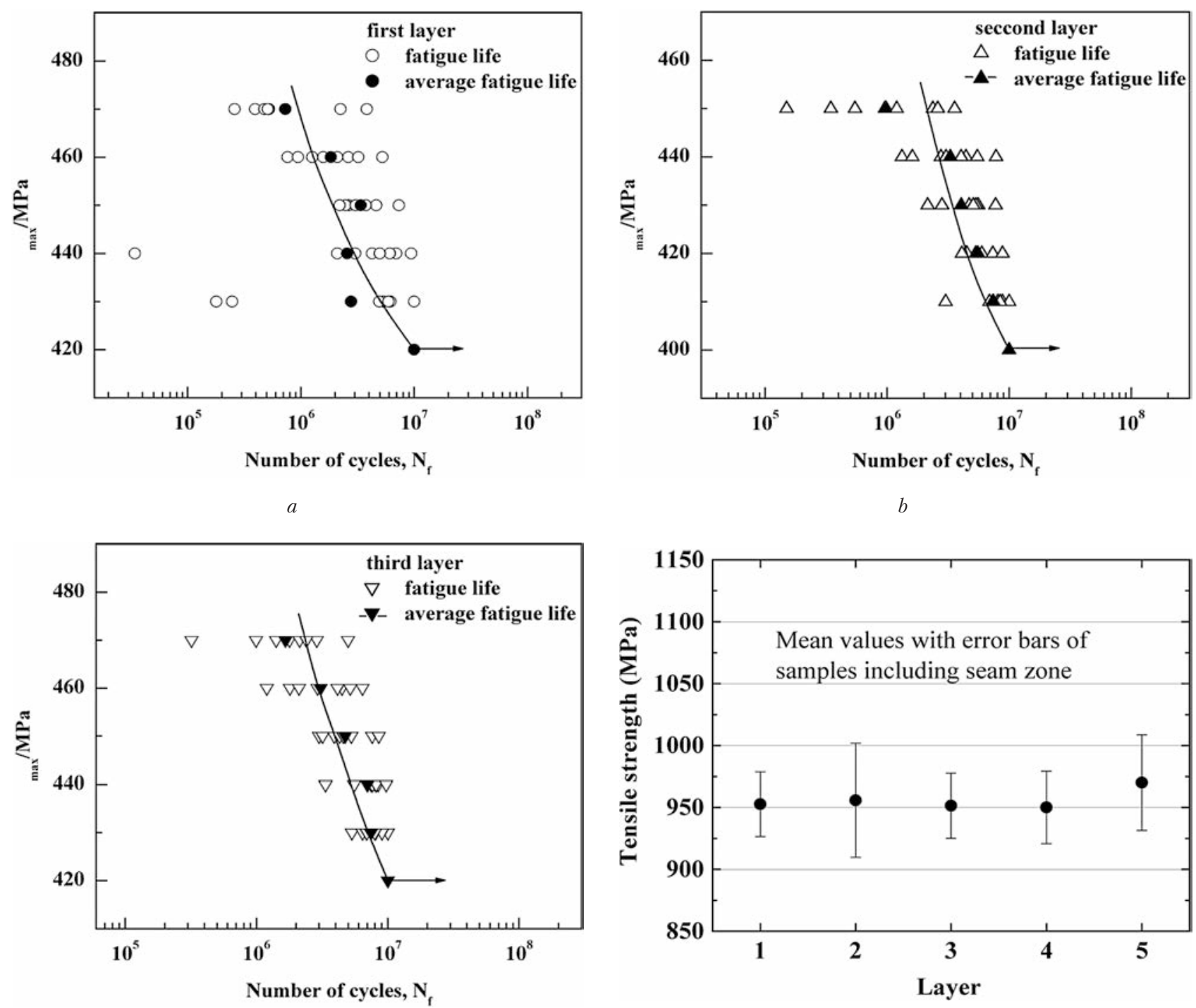

Fig. 3. The fatigue S-N curves of the joint, $a$. S-N curve of layer $\mathrm{l}_{1}, b$. S-N curve of layer $\mathrm{l}_{2}, c$. S-N curve of layer $\mathrm{l}_{3}$, $d$. the tensile properties of different layers 


$$
s=\sqrt{\frac{1}{n-1} \sum_{k=1}^{n}\left(x_{k}-\bar{x}\right)^{2}}
$$

The standard normal deviation $\left(u_{p}\right)$ could be got by checking the normal distribution function value table and the survival probability $\left(1-p_{f}\right)$, and hence the fatigue life with the survival probability can be calculated by formula 3 and formula 4 . The $x_{p}$ represent the logarithm fatigue life of the specimens, the $N_{p}$ is the calculated fatigue life. By calculated the $N_{p}$ values of the specimens represent different layers the P-S-N curves can be got in Fig. 4 .

$$
\begin{gathered}
x_{p}=\bar{x}+u_{p} s \\
N_{p}=10^{x_{p}}
\end{gathered}
$$

In Fig. 3, the hollow points represent the fatigue life under different stress levels. The solid points represent the average fatigue life under different stress levels. It could be seen that the fatigue strength of the layers are $420 \mathrm{MPa}\left(l_{1}\right), 400 \mathrm{MPa}\left(\mathrm{l}_{2}\right)$ and $420 \mathrm{MPa}\left(l_{3}\right)$. The layer $l_{2}$ has relatively lower fatigue strength value. Compared with the tensile properties of the joint (Fig. $3 d$ ), it is clearly that the middle layers also have relatively lower tensile strength. It could be seen in the Fig. $2 a$ the middle layers have relatively finer textures. The low fatigue strength could only be attribute to the forging defects such as the residual casting structures, vortex and inner crack origination by the forging stress, which have been coming with the base metal, because the forging stress is relatively high and the forging defects are sensitive in the middle layer of the thick plate. It could also be seen that all the fatigue specimens of the 3 layers survive after the $10^{7}$ tensile $400 \mathrm{MPa}$ loading cycles. The joint welded by EBW has good fatigue resistance capability at the $400 \mathrm{MPa}$.

The fatigue life points of the 3 layers at different stress levels show the same trend, namely the distribution of the points at the lower stress levels are more concentrated, and the data points are dispersed under higher stress levels. That means the fatigue life of the specimens have big differences under high level stress. Since the cyclic waveform is the sinusoid and the specimens were tested at $100 \mathrm{~Hz}$ frequency, actually the distribution of the data points have relation with the loading rate. The high loading rate and the increasing loading force result dispersed distribution of the data point, and the lower loading rate and loading force could concentrate the data point. It can also be seen from Fig. 3 that most specimens survive after loading $10^{5}$ cycles even at the higher stress level (460 MPa), the specimens tested at the $440 \mathrm{MPa}$ could survive after the $10^{6}$ cycles' load. The fatigue life of the second

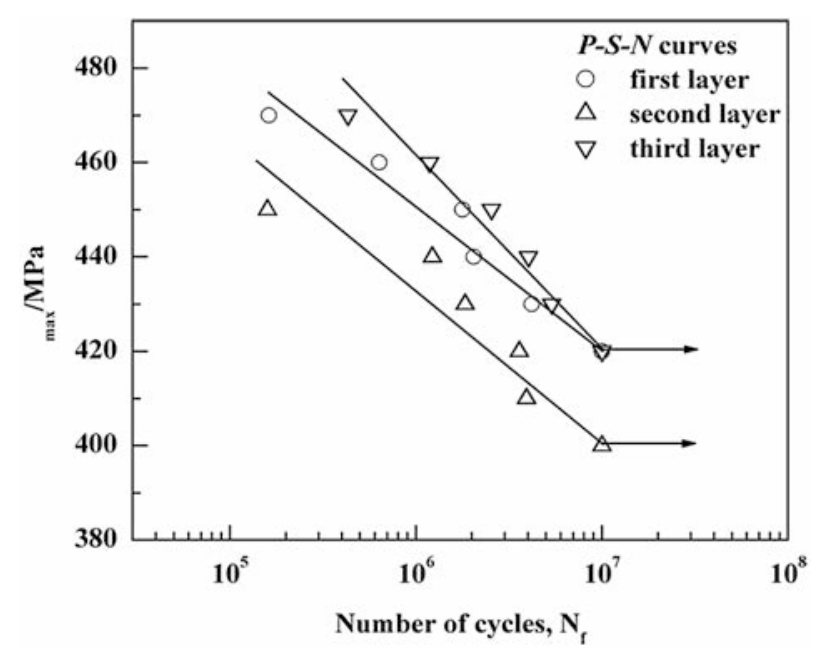

Fig.4. The comparison of the P-S-N curves of different layers

layer, namely the middle layer of the joint, have lower fatigue life at the same stress level. Fig. 4 show the comparison of the P-S-N curves of the 3 layers. It can be seen directly that the fatigue life of the $l_{3}$ layer under the $95 \%$ joint survival rate is higher than that of the $l_{1}$, and the fatigue life of the $l_{2}$ is the lowest one.

The fatigue crack propagation rate could be depicted by the following formula (see table1) proposed by Paris [6]. The a represents the length of the fatigue crack, the $N$ is the loading cycle number, the $d a / d N$ represent the fatigue crack propagation rate, $\Delta K$ is the stress intensity factor of the crack tip, $C$ and $m$ are the material constants which have relationships with the experiment conditions. The calculated $C$ and $m$ of the specimens taken from the 3 layers could be seen in Table 1, through which the fatigue crack propagation rate of the Ti- $6 \mathrm{Al}-4 \mathrm{~V}$ joint could be expressed by the formula 5 as functions between the $d a / d N$ and the $\Delta K$. It could be found the trend by comparing the data in table1. If the $\Delta K$ is the same value, the crack propagation rate of the layer $l_{2}$ is the highest in the 3 layers. These results could further convince the conclusions of the P-S-N curves in the end of last paragraph. Further

Table 1

Calculated constants of the crack propagation rate

\begin{tabular}{|c|c|c|c|}
\hline \multicolumn{2}{|c|}{ Specimen No. } & $\boldsymbol{C}$ & $\boldsymbol{m}$ \\
\hline \multirow{3}{*}{ Layer $1_{1}$} & $1 \#$ & $4.96 \times 10^{-11}$ & 4.60 \\
\cline { 2 - 4 } & $2 \#$ & $1.20 \times 10^{-12}$ & 5.64 \\
\cline { 2 - 4 } & $3 \#$ & $3.59 \times 10^{-14}$ & 6.71 \\
\hline \multirow{3}{*}{ Layer $1_{2}$} & 4\# & $3.28 \times 10^{-10}$ & 4.42 \\
\cline { 2 - 4 } & $5 \#$ & $2.12 \times 10^{-11}$ & 5.21 \\
\cline { 2 - 4 } & $6 \#$ & $1.85 \times 10^{-12}$ & 4.11 \\
\hline \multirow{3}{*}{ Layer $_{3}$} & $7 \#$ & $2.93 \times 10^{-14}$ & 6.83 \\
\cline { 2 - 4 } & $8 \#$ & $4.35 \times 10^{-16}$ & 8.24 \\
\cline { 2 - 4 } & $9 \#$ & $3.46 \times 10^{-16}$ & 7.97 \\
\hline
\end{tabular}


work needs to be done to clarify the precise stress differences of the 3 layers, though we have already could deduce the differences of the stress between the layers are relatively small, which cannot change the trend of the fatigue life comparison of the layers (layer $l_{1}, l_{2}$ and $l_{3}$ ).

$$
\mathrm{d} a / \mathrm{d} N=C(\Delta K)^{m}
$$

\subsection{Fatigue fracture surface analysis}

Fig. $5 a$ shown the fatigue crack origination zone of the specimens taken from the 3 layers, which were tested at $450 \mathrm{MPa}$. Fig. $5 b$ is the representative results of the microstructure of the fatigue fractures at $440 \mathrm{MPa}$. The arrows in Fig. $5 a$ point to the free surface. The results indicate that the fatigue cracks of the 3 layers originated at the free surfaces by the transgranular fracture mode, because the fatigue striations could be found in the morphologies of the fatigue propagation regions in all 3 layers (Fig. $5 b$ ). That means the 3 layers have the same fracture mode at $450 \mathrm{MPa}$. The microstructures of the fatigue fracture surfaces can be seen in the right side of the Fig. 5b. Low-density dislocation walls can be found in the specimen of the layer $l_{1}$ in Fig. $5 b$, and the dislocation blocks can also be found between the dislocation walls. The explicit dislocation walls can be found in the specimen of the layer $l_{2}$ either, there are dislocation lines in different slipping directions which could be seen between the dislocation walls, no dislocation blocks were found between the dislocation walls. The low-density dislocation walls also were found in the specimen of the layer $l_{3}$, however there are few dislocation lines were found between the dislocation walls.

The results shown that the deformation mechanisms of the joint at 3 layers under high cycle fatigue are all planar-slip deformation mechanism. In the 3 layer, some of the dislocations show the dislocation wall characteristics, and the dislocation wall is formed by lots of short dislocations having the same orientation. The grain boundaries, the sub-grain boundaries and the phase boundaries are the zones in which the dislocation walls tend to easily form. The interactions between the boundaries and the dislocations usually be very complicated. The dislocation walls could react with the solo dislocation, the grain boundaries and the phase boundaries, as well as the sub-grain boundaries, which would be harmful for the fatigue life of the specimens.

\section{Conclusions}

1. The Ti-6Al-4V $100 \mathrm{~mm}$ thick part were welded by the EBW method under vacuum condition. The joint has heterogeneity not only in the microstructure but also in fatigue properties.

2. In the thickness direction, the microstructure of the seam has basket-weave microstructures, including acicular martensite and dendrite phases. The dendrite

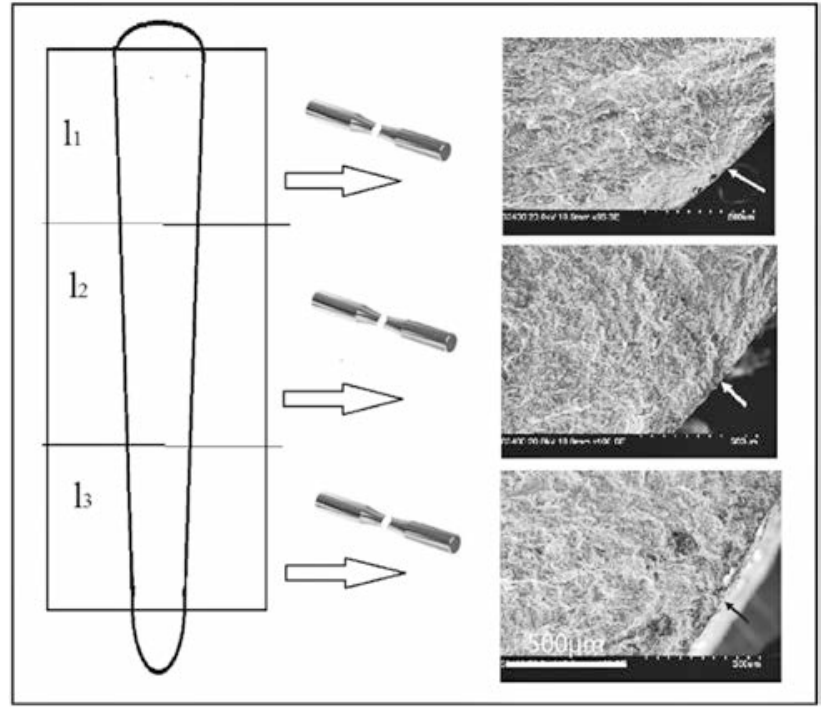

$a$

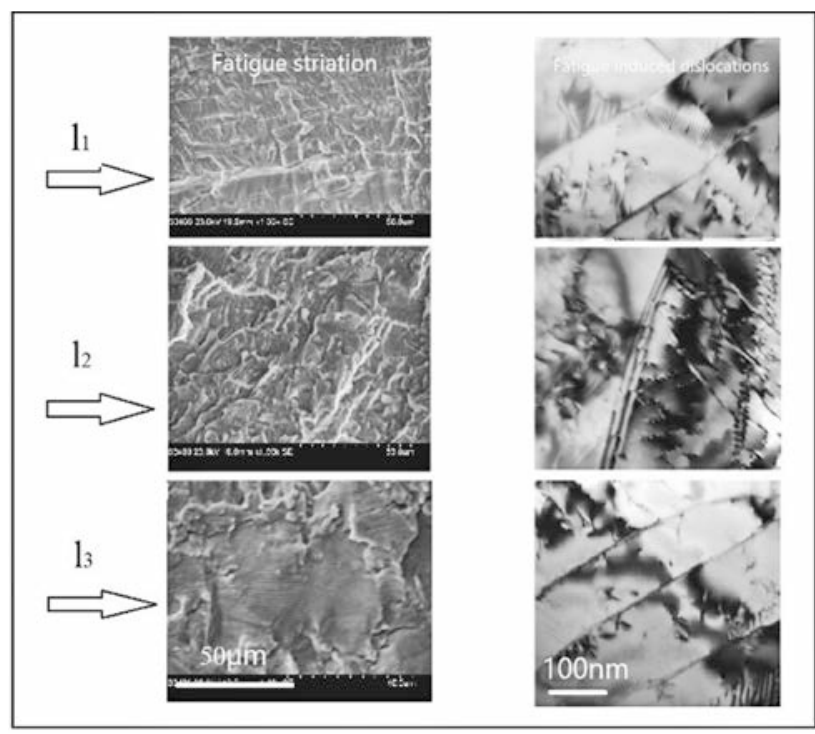

$b$

Fig. 5. Fatigue fracture surface observation of the layers in the thickness direction, $a$. fatigue crack origination, $b$. fatigue striations and dislocations observation

crystals have the trend to become finer and finer in the thickness direction from the upper seam surface to nail tip direction surface. The microstructures of the HAZ have the trend to change from widmannstatten structure, crumby structure to basket-weave structure.

3. The fatigue strength under $10^{7}$ cycle load of the layer $l_{2}$ is lower than those of the layer $l_{1}$ and layer $l_{3}$. The fatigue life of the $l_{3}$ layer under the $95 \%$ joint survival rate is higher than that of the $l_{1}$, and the fatigue life of the $l_{2}$ is the lowest one. The fatigue crack propagation functions have been got by the Paris formula and the experimental conditions.

4. The fatigue crack of all the 3 layers originated on the free surface and have transgranular fracture mode with the 
crack propagation. The dislocation wall structure could be found in the specimens taken from each layer. The fatigue deformations of the joints develop with the changing of the dislocations in the planar-slip mechanism.

Acknowledgement

This work is supported by the funding of the projects No. 2016B070701025, No. 2014B070705007, No.2017A070701026, No. 2017GDASCX-0113, Pangang project-2014-03 and 2015-10

\section{References}

[1] Zhang HT, He P, Feng JC and Wu HQ, (2006) Interfacial microstructure and strength of the dissimilar joint $\mathrm{Ti}_{3} \mathrm{Al} / \mathrm{TC} 4$ welded by the electron beam process, Mater. Sci. and Eng. A 425: 255-259
[2] Barreda JL, Santamar Hma F, Azpiroz X, Irisarri AM, and Varona JM, (2001) Electron beam welded high thickness Ti6Al4V plates using filler metal of similar and different composition to the base plate, Vacuum, 62: 143-150

[3] Hu MJ and Liu JH, (2009) Effect of zonal heat treatment on residual stresses and mechanical properties of electron beam welded TC4 alloy plates, Trans. Nonferrous Met. Soc. China 19: 324-329

[4] Lu W, Shi YW, Lei YP and Li XY, (2012) Effect of electron beam welding on the microstructures and mechanical properties of thick TC4-DT alloy, Materials and Design 34: 509-515

[5] Li QH, Hu SB and Li XZ et.al., (2010) Microstructure Heterogeneity and Fatigue P roperty of WeldJoints of TC4 Titanium Alloy, Mat. Eng. China 1: 62-68

[6] Paris P, Erdogan F, (1963) A Critical Analysis of Crack Growth Laws. Journal of Basic Engineering, Transaction of the ASME, 85: 528-5341

УДК 621.791 .03

Zhang YP, Dong CL, Wang YQ*, Hou B, Yu C, Fang WP, Xu WH

Центр передовых материалов, Институт сварки провинции Гуандун (Китайско-Украинский институт сварки им. Е. О. Патона). Гуанчжоу, 510651, Китай

\title{
МНОГОЦИКЛОВАЯ УСТАЛОСТЬ СОЕДИНЕНИЙ ТОЛСТЫХ ПЛАСТИН ИЗ СПЛАВА Ті-6V-4V ПОЛУЧЕННЫХ ЭЛЕКТРОННО-ЛУЧЕВОЙ СВАРКОЙ
}

\begin{abstract}
Пластины Ti-6Al-4V толщиной 100 мм сваривали методом электроннолучевой сварки (ЕВW). Изучены микроструктуры и механические свойства, включая поведение соединения при растяжении и усталостном разрушении. Результаты показали, ито соединение имеет явную текстурную и механическую неоднородность по толщине, демонстрирует превосходное сопротивление усталости, хотя средний слой соединения имеет меньшую усталостную долговечность при одинаковом напряжении и числе циклов. Усталостная трещина начинается со свободной поверхности образца по типу трансгранулярного разрушения. Усталостная деформащия, отображаемая дислокачиями в каждом слое соединения, адаптируется к механизму плоского скольжения. [dx.doi.org/10.29010/88.10]
\end{abstract}

Ключевые слова: Ti-6Al-4V, микроструктура, механические свойства, усталость.

\section{Литература}

[1] Zhang HT, He P, Feng JC and Wu HQ, (2006) Interfacial microstructure and strength of the dissimilar joint $\mathrm{Ti}_{3} \mathrm{Al} / \mathrm{TC} 4$ welded by the electron beam process, Mater. Sci. and Eng. A 425: 255-259

[2] Barreda JL, Santamar Hma F, Azpiroz X, Irisarri AM, and Varona JM, (2001) Electron beam welded high thickness Ti6Al4V plates using filler metal of similar and different composition to the base plate, Vacuum, 62: 143-150

[3] Hu MJ and Liu JH, (2009) Effect of zonal heat treatment on residual stresses and mechanical properties of electron beam welded TC4 alloy plates, Trans. Nonferrous Met. Soc. China 19: 324-329

[4] Lu W, Shi YW, Lei YP and Li XY, (2012) Effect of electron beam welding on the microstructures and mechanical properties of thick TC4-DT alloy, Materials and Design 34: 509-515

[5] Li QH, Hu SB and Li XZ et.al., (2010) Microstructure Heterogeneity and Fatigue P roperty of WeldJoints of TC4 Titanium Alloy, Mat. Eng. China 1: 62-68

[6] Paris P, Erdogan F, (1963) A Critical Analysis of Crack Growth Laws. Journal of Basic Engineering, Transaction of the ASME, 85: 528-5341 